\title{
The Lightning Jump, the 2018 "Picking up Hailstones" Campaign and a Climatological Analysis for Catalonia for the 2006-2018 Period
}

\author{
C. Farnell ${ }^{1}$ and T. Rigo ${ }^{1}$ \\ ${ }^{1}$ Servei Meteorològic de Catalunya \\ Received: 16-VIII-2019 - Accepted: 11-V-2020 - Original version
}

Correspondence to: carme.farnell@gencat.cat

\begin{abstract}
Previous analysis in Catalonia (NE Iberian Peninsula) demonstrated the high correlation between Lightning Jump (LJ) algorithm warnings and the occurrence of severe weather. The algorithm was put into operations in the Servei Meteorologic de Catalunya (SMC) (Meteorological Service of Catalonia) in 2016, exclusively considering lightning data. We found that more than $80 \%$ of the alerts were associated with at least one severe weather register in the area of study. This percentage could be even higher because of the lack of observations in some events that occurred in low-density population areas or at night. To collect surface registers that improve the information associated with the phenomena that occurred in severe thunderstorms in 2017, we started a citizen campaign (called "Plega la pedra", translated as "Picking up Hailstones" using social networks (mainly, twitter-\#meteocatpedra- and a WhatsApp channel). Thanks to the high contribution of the citizen campaign, the number of registers were higher than the average in comparable situations for previous years. The first part of this paper shows how it is functioning in the SMC, and the campaign results reported during 2018. The second part of the analysis consisted of a complete climatological study of its behavior in Catalonia, based on 13 years of data related to LJ alerts available. The study considered some characteristics such as the lead time, or the spatial, the monthly and yearly distributions. These features were compared and matched to severe weather observations recorded during this period in the same area. This analysis can help us to better understand the thunderstorms which triggered the warnings and the relationship between the alert and the severe weather observations on the surface.
\end{abstract}

Key words: Lightning Jump, hail climatology, observations, validation

\section{Introduction}

Severe weather has been studied for years in Catalonia (NE Iberian Peninsula) (e.g. Tudurí and Ramis (1997); Pascual (2000); Pascual et al. (2004)). The phenomena in a severe thunderstorm in Catalonia can be hailstones of more than $2 \mathrm{~cm}$ in diameter, downbursts, convective wind gusts of up to $25 \mathrm{~m} / \mathrm{s}$, and tornadoes. In addition, some of the works found an increase of electrical charge in the thunderstorm related to severe weather studied in different episodes (Ramis et al., 1997; López, 2007; Aran et al., 2009). This phenomenon, named Lightning Jump (LJ), was detected in other places of the world in very similar atmospheric situations (Williams et al., 1999; Stano et al., 2014; Bridenstine et al., 2005; Yao et al., 2013; Darden et al., 2010).

The Servei Meteorològic de Catalunya (SMC) began a project to set up in real-time an algorithm capable of detecting the jump in thunderstorms in Catalonia. The first version consisted of an adaptation of the $2 \sigma$ (Schultz et al., 2011), which is based on the tracking of thunderstorms for 14 minutes. Then, the procedure considers only the strongly active cells during the entire period. Finally, it searches for a big variation in the last minute that exceeds the double of the standard deviation of the previous 14 minutes. The period and the threshold values were obtained 


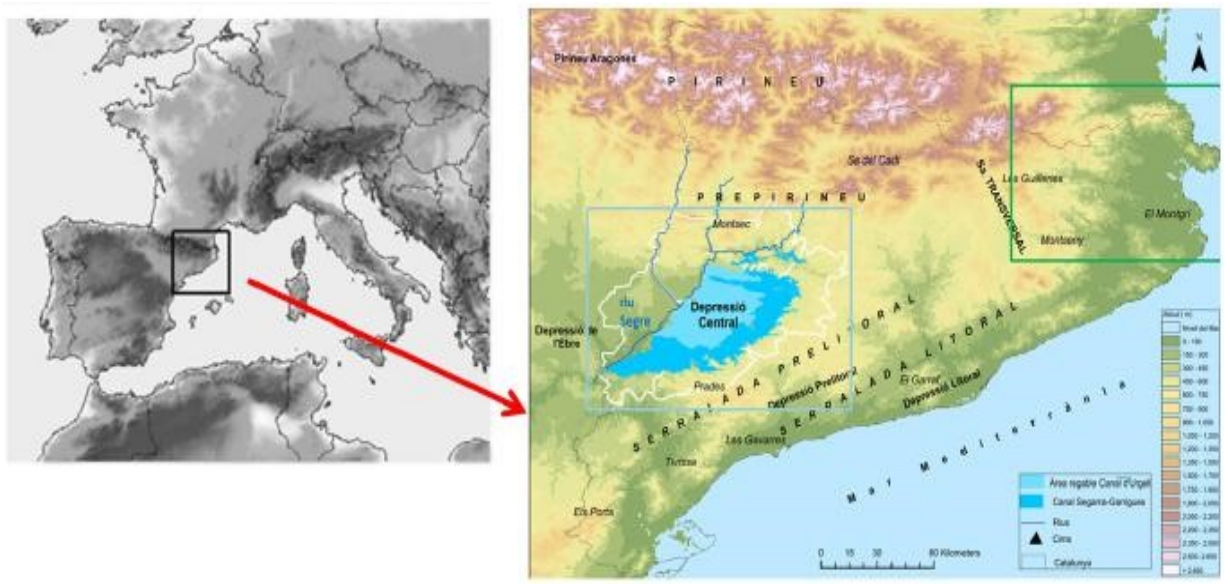

Figure 1: Left: Map of Western Europe. Right: Zoom in on the area of interest.

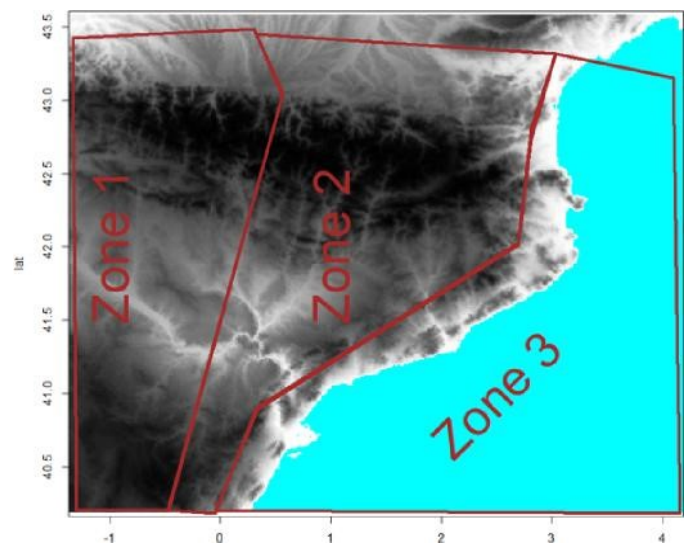

Figure 2: Separation of the area into three regions: interior (zone 1), middle (zone 2), and coastal area (zone 3 ).

empirically by (Schultz et al., 2009). One of the main differences between the original version is considering the SMC Lightning Location System (LLS, or XDDE, Xarxa de Detecció de Descàrregues Elèctriques) instead of a Lightning Map Array (LMA) (Schultz et al., 2011). The number of detected sources, which is notably lower than in the original research, is enough to implement the procedure in the right way. Furthermore, it makes the real-time application of the algorithm (Farnell et al., 2017) easier. In addition, it covers a larger area than the LMA installed in Catalonia (Pineda et al., 2016). The main goal of the project was the improvement of severe weather forecasting in the study area. The implementing process of the algorithm had different steps. Firstly, the tool ran off-line over a set of severe weather episodes recorded in Catalonia during the 2006-2013 period. In view of the good results obtained, the algorithm moved to the pre-operational stage in 2016 and became operational the following year. Farnell et al. (2017) and Farnell et al. (2018) described the methodology and results obtained during this period.

There have been some significant advances in severe weather analysis since the 2000s with the improvement of the technology in many countries around the world (Gabella et al., 2016; Crum et al., 1998). On the other hand, the increase of the presence of smartphones, which allow photos and videos to be recorded, has helped to compile a lot of severe weather-related observations (Ortega et al., 2016; Llasat et al., 2018). In this sense, the combination of better data sources and more ground records has allowed severe weather nowcasting to improve. This is the baseline of the current manuscript.

This article is a summary of the different parts of the process of severe weather warnings generated in Catalonia. It also presents a citizen campaign (\#Plegalapedra), used to obtain severe weather-related registers. These data help to validate the $\mathrm{LJ}$ alerts in those cases with official values. The second study considered a climatological analysis by applying the algorithm to all severe weather episodes that happened between 2006 and 2018. The results helped to introduce a climatology of severe weather in Catalonia. In addition, they allow the orography effects and the Mediterranean Sea to be associated to the severity of the thunderstorms in Catalonia during the year. The text begins with descriptions of the study area and the operational algorithm. Then, the results obtained during 2018, the campaign \#Plegalapedra and a climatological study (20062018) are presented. Finally, there is a brief discussion about different aspects of the algorithm, the conclusions and the future implications in the operational chain of the SMC to conclude the article.

\section{Area of study}

Catalonia is located in the NE of the Iberian Peninsula (Fig. 1). The Mediterranean Basin contributes to convective and baroclinic structures with high amounts of heat and moisture. It interacts with the rugged topography of the region, which helps to lift the low-level, conditionally unstable air-mass. In other words, the combination of both factors initiates the condensation and convection processes that produce most adverse weather episodes in the region (Ducrocq et al., 2014; Llasat Botija et al., 2010; Jansa et al., 

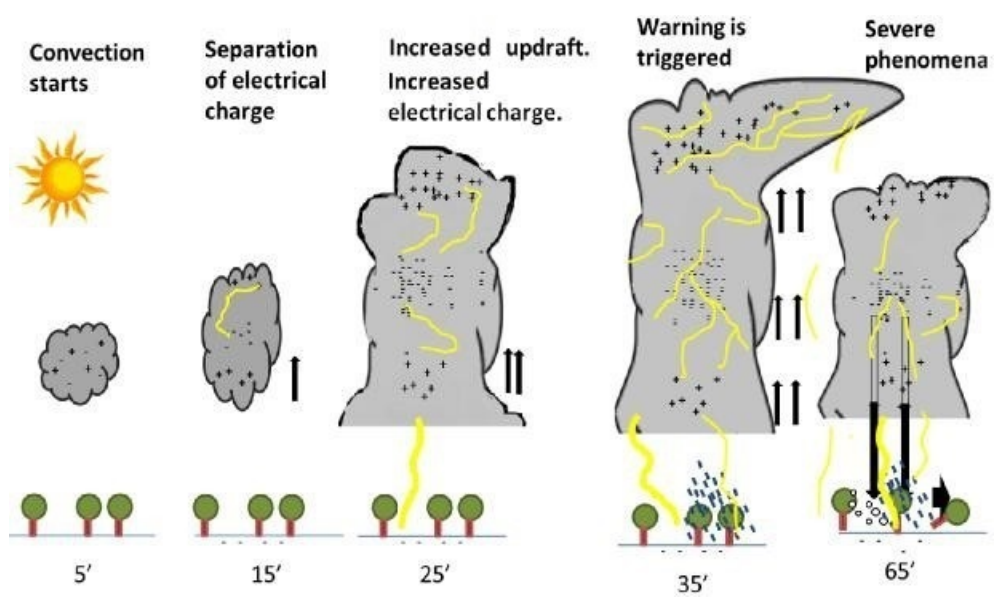

Figure 3: Theoretical model of the phenomena of Lightning Jump and the occurrence of associated severe weather.

2000). In this sense, this configuration plays an important role in the severe weather or the heavy rain occurrence in Catalonia (as in other regions of the Mediterranean Basin).

The area of study (Catalonia and its vicinity) has been divided into 3 regions (see Fig. 2), with the principal goal of understanding the contributions of the topography and the Mediterranean Sea. The inland area (zone 1) shows a small maritime contribution and a significant impact of the topography in the north and south. The second area is the border between the other two regions. The Mediterranean Sea has a notable influence on this region. The topography plays an important role, but, in any case, less so than in the previous zone. Lastly, the coastal part is more affected by maritime influence than the topography impact.

\section{Description of the operational algorithm of the Lightning Jump at the SMC}

Fig. 3 is a conceptual scheme similar to the one shown in Price (2013), but adapted to severe weather thunderstorms in the area of study. The life cycle includes 5 phases that begin when the convection starts, due to unstable atmospheric conditions. A few minutes later, the updraft produces a separation of electrical charge and the first intra-cloud flashes (IC) occur. The thunderstorm continues growing because of the strong updraft and then, the cloudto-ground (CG) also occur. If the electrical activity is very high, and the strong updraft remains, a sudden increase in this activity can occur. Williams et al. (1999) defined this phenomenon as a Lightning Jump (LJ). Minutes after this increase, severe weather generally occurs on the surface. The lead time (LT), or the difference between the jump and the ground phenomenon, depends on the thunderstorm type (squall line, supercell, multicell, among others).

The detection process of the LJ phenomenon starts with the identification of thunderstorms. The procedure is different with respect to the majority of the techniques developed in this sense (e.g. Schultz et al. (2011); Darden et al. (2010); Gatlin and Goodman (2010)). The technique applied here (Farnell et al., 2017) only uses electrical discharges without radar data. This process is optimum at the operational level because the temporal resolution is 1 minute. However, when combining radar and lightning data, the temporal resolution is 6 minutes plus a 5 -minute delay caused by the radar product generation. The negative point resides in those areas where the LLS coverage is not good enough. There, the identifications are not as accurate as in combined radar and lightning data. Fig. 4 does not show substantial differences between identification techniques in areas with good coverage.

The identification process used in the SMC is similar to other algorithms which work with radar images (Dixon and Wiener, 1993; Johnson et al., 1998; Rigo and Llasat, 2016; del Moral et al., 2018). The method transforms the preliminary dot data into a georeferenced matrix or raster. The process used is rasterization, found in the raster package of R software (Hijmans, 2017; R Core Team, 2013). From now on, the method remains similar to the previously cited radar techniques. First, it combines the thresholding of the number of discharges and the number of pixels (see Fig. 4, bottom panel). The next phase is the calculation of the centroid of the structure through the coordinates and electrical density at each point. From the centroid identification of the thunderstorm, the convective cell characterization includes different parameters: centroid coordinates, time and data, the total number of discharges and the area.

The $\mathrm{LJ}$ issues a warning when various conditions occur at the same time (top panel of Fig. 5). The first one is that the thunderstorm must last for at least 14 minutes. Once the complete identification occurs, the procedure analyzes the path considering previous observations. The track on previous imagery of a particular cell takes into account a distance threshold. If there is a coincidence, the current cell will have the same identification number as in the previous time. This process is repeated for 14 minutes searching for continuity in space and time. As explained earlier, in the 


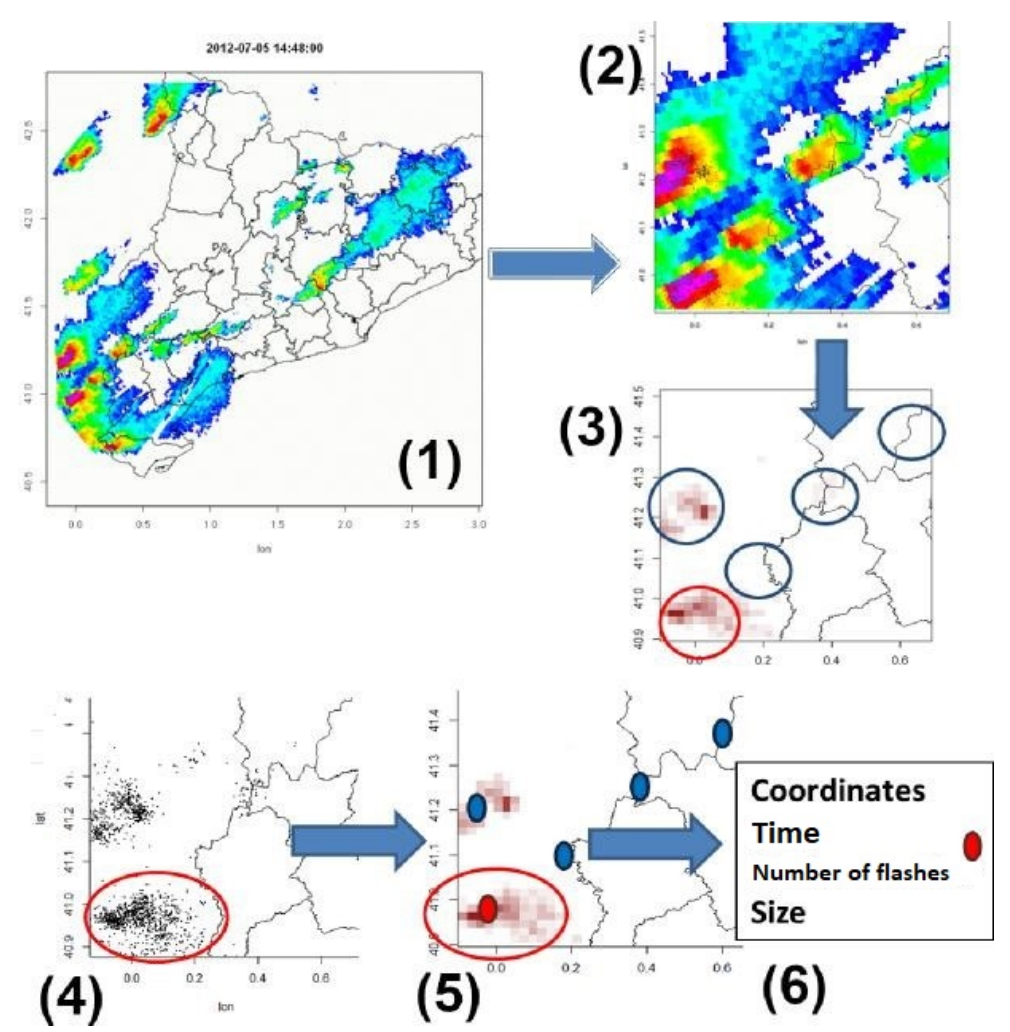

Figure 4: Top: Different thunderstorms identified by radar and electrical discharges. (1) Whole radar image for 5 July 2012 at 14.48 UTC. (2) Same image zoomed in to the thunderstorms in the bottom-left part of the previous image. Black dots indicate the location of flashes for the period between 14.43 and 14.48 UTC. (3) Flash density for the same area as in (2). The ellipses (blue or red) mark the different thunderstorms detected by the weather radar. Red indicates a possible candidate to be analyzed because of the elevated TL flashes detected inside and the contiguous vicinity of the thunderstorm. Bottom: Characterization of each thunderstorm through its centroid and its properties. (4) and (5) images are equivalent to (2) and (3), but focused exclusively on lightning data. (6) Summary of the characteristics of each cell identified in (5).

original method a threshold was applied to consider whether a pixel belonged or not within a cell. However, in the current technique, this constraint has not been used because the 14-minute continuity indicates that the cell has enough entity. However, this fact does not indicate whether this thunderstorm is severe or not.

If a thunderstorm meets the previous criteria, the tool calculates the number of flashes in seven periods $(\mathrm{P})$ of two minutes, to avoid anomalies associated with the bad performance of the network. Then, the next step is to calculate the average for every two minutes (Fig. 5, below). If the period $j$ includes the 1-minute values $X_{i}$ and $X_{i+1}$, its value $P_{j}$ will be the average of $X_{i}$ and $X_{i+1}$. For instance, the 6 th period will be $P_{6}=\left(X_{11}+X_{12}\right) / 2$. The last step considers the division of the changing time variation of the total flash rate $(D F R D T)$ into 6 periods. Then, the 5 th period is $D F R D T_{5}=P_{6} P_{5}$. In the case of the last period, we define $D F R D T$ as $D F R D T_{6}=X-P_{6}(X$ is the label of $\left.P_{7}\right)$. Finally, it calculates the standard deviation $(\sigma)$ for the first six periods $\left(P_{1}, \ldots, P_{6}\right)$, and compares its value with $X$. If $X$ is larger than $2 \sigma$, the algorithm issues a warning.

This process is executed in real time every minute, with an imbalance of 1 minute to incorporate the data into the database in question. As explained before, this frequency is very important for operational surveillance tasks. When the alert is activated, an email is sent to the forecast team to facilitate their job. This mail includes the coordinates and location where the $\mathrm{LJ}$ is activated, the data, time and warning level. Then, the forecaster can observe the tool that shows what areas are the most likely to be affected by the thunderstorm (probability cone generated from radar data).

There are two types of operational warnings in the SMC procedure: based on whether it is considering or not the multiplicity of the flashes. The multiplicity consists of identifying one lightning through several energy strokes, instead of a unique energy stroke (non-multiplicity case). This second option is known as "without multiplicity". Multiplicity allows for better identification and tracking processes of the thunderstorm. However, thunderstorms with multiplicity warnings are normally less active and the alerts are not always related to severity. From the 2017 and 2018 campaigns, we observed that thunderstorms with only multiplicity warnings have less intense updrafts.

\section{Results}

\subsection{The 2018 operational campaign}

Fig. 6 shows the alerts detected at both levels. On the one hand, level 1, with multiplicity (LJ1), associated with non-severe surface phenomena (hail $<2 \mathrm{~cm}$, moderate gusty wind and/or intense rainfall in a short time). On the other 

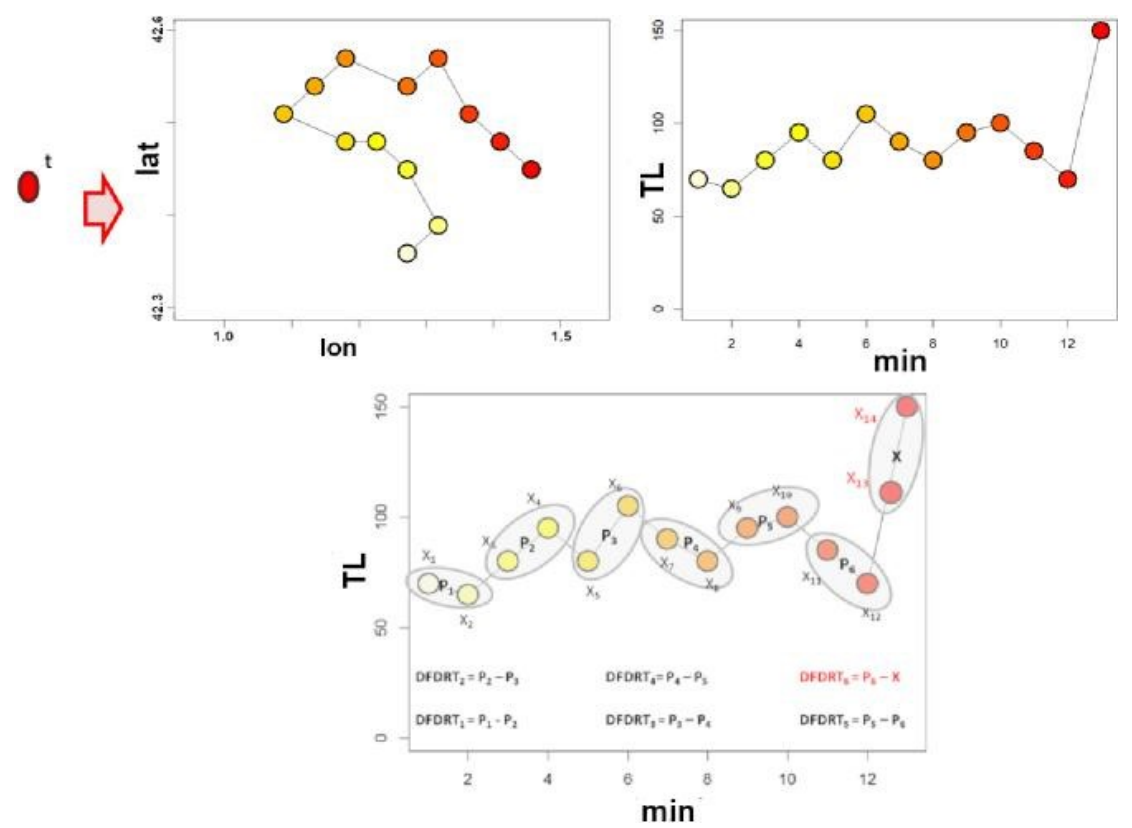

Figure 5: Top: example of spatial (left) and time (right) continuity of a thunderstorm during the time necessary to be evaluated. White and yellow indicate the preliminary stage (first 5 minutes), orange corresponds to the mid-stage, and red to the last part (last 5 minutes). Bottom: Total lightning (TL) per minute, grouped into periods of 2 minutes and differences between periods.

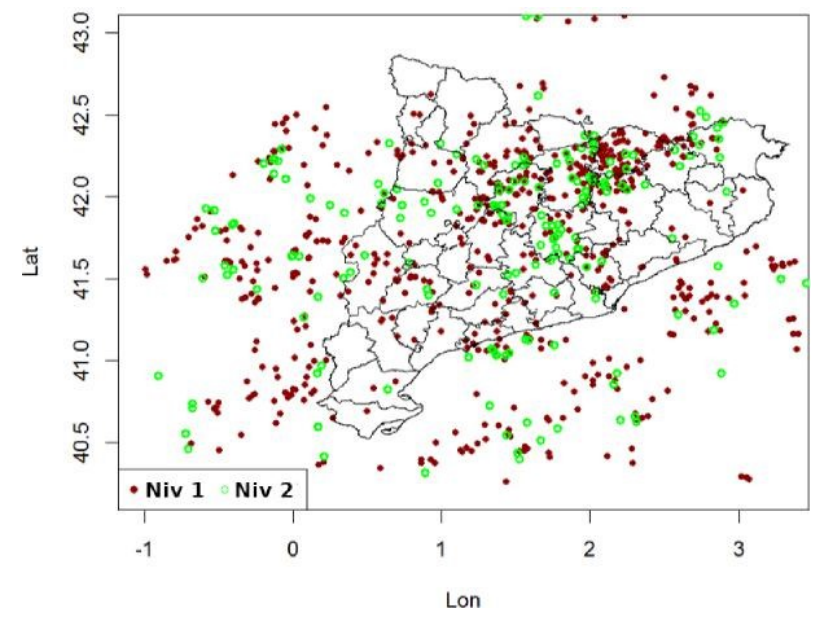

Figure 6: Alerts produced during 2018: level 1 (violet) and level 2 (green).

hand, level 2, without multiplicity (LJ2), which produces severe weather on the surface (large hailstones, downburst, strong gusty wind, tornadoes, and heavy rainfall). The number of LJ1 warnings was more significant than the LJ2 ones in the 2018 campaign because reaching adequate vertical development to produce severe weather-related phenomena is complex. However, moderate thunderstorms are more common throughout the year. The 2018 ratio was 0.3 level 2 warnings for each level 1 warning. This value varies over the years, but it moves between 0.25 and 0.4 (see more details in subsection 4.2), approximately. The warnings can be issued throughout Catalonia and the surrounding area. In any case, the Pre-Pyrenees was the most affected area in 2018, similar to the 2006-2018 period (again, more information in subsection 4.2).
To understand how the LJ algorithm works, Fig. 7 shows two specific episodes reported in 2018. Firstly, the event recorded on the 7th of January in which large hailstones and some tornadoes occurred. This situation was very unusual because the majority of the severe weather in Catalonia happens between June and September. Fig. 7 presents the thunderstorm track that started over the sea and moved to the north. During the path, the cell produced hailstones of around $3 \mathrm{~cm}$ and a tornado next to the border with France. In the same figure, the Cone of Probability indicated the most probable direction that the thunderstorm would follow in the next two hours just at the time the warning was set off. This tool is used by forecasters to define the area which can be affected by severe weather over the next 120 minutes. In this example, the lead time between the alert and the severe weather register moved between 32 and 88 minutes. The second example shows the episode of 9th October, when 6 warnings were set off (Fig. 7 shows one of them). The thunderstorms affected populated coastline regions but did not produce registers of severe weather on the ground. Then, the citizen campaign \#PlegalaPedra was created in 2017 (http://www.meteo.cat/wpweb/observacions/campanyameteocatpedra/) to deal with gaps in the database in events like this one. The main goal of this campaign was to compile observations with a full information report (time, size, place and a photo). These registers help to validate the different products developed in the SMC related to the forecasting and diagnosis of hail and the LJ algorithm, in particular.

Fig. 8 shows the main activity of severe weather episodes in Catalonia during 2018, through the information compiled during the \#PlegalaPedra campaign. These registers have been validated thanks to the citizen photos and additionally, 


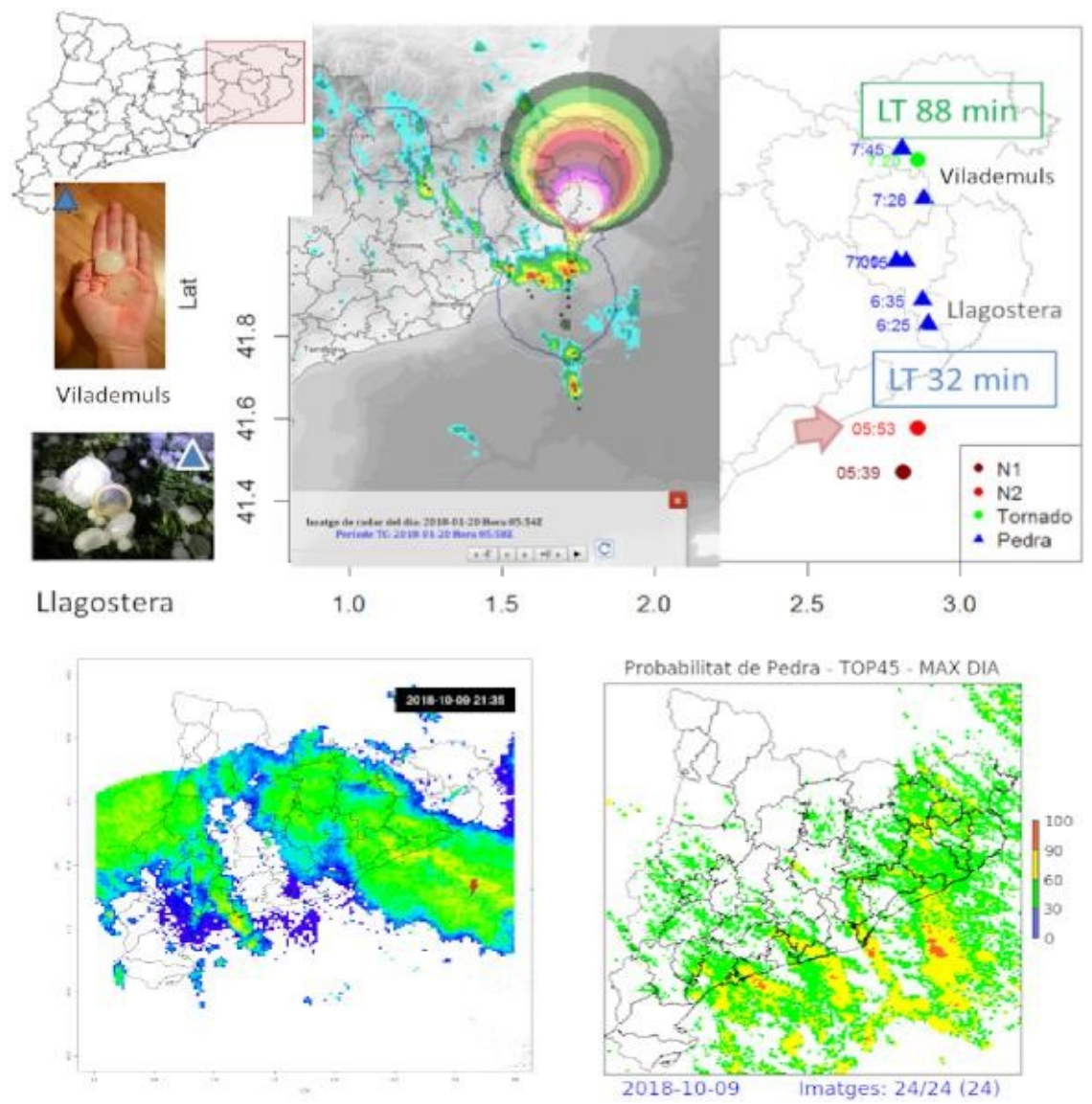

Figure 7: Top: working of the tool for the 7th January 2018 episode. The lead time was between 32 and 88 minutes. Bottom: Episode of 9 th October 2018. During this case, the SMC did not receive any observation, and was a reason for creating the \#PlegalaPedra campaign and increasing the contribution of the civil population.

by using SMC automatic weather stations or remote sensing data, especially radar and lightning information.

The lead time for 146 cases has been analyzed by comparing the alerts represented in Fig. 5 and the observations included in Fig. 8. The first group of the analysis includes thunderstorms that the alert jumped later than the ground record ( $8 \%$ of cases). The lead time was between 30 and a few minutes in $46 \%$ of cases (Fig. 9). It is worth noting that most of those thunderstorms had quasi-stationary behaviour. In these cases, the warning is usually produced just in time with the observation. Besides, these thunderstorms occurred in mountain areas, like the Prepirinea zone. The last group, which includes the $46 \%$ remaining cases, considers those events in which the warning jumped 30 minutes or more before the severe weather observation happened. However, in some cases results difficult the identification of the exact moment in which the record occurred. Some examples are when the thunderstorm happens during the night, it affects areas with small density population, or the damages are scarce.

In the last part of this analysis, the monthly and hourly (Fig. 10 top and bottom, respectively) distributions of the LJ warnings and the severe weather observations recorded during 2018 were studied. Regarding the alerts, the behavior is very similar on the two levels, but the number of LJ1s is more significant than LJ2s. This distribution shows a maximum in August and a minimum in November. This behavior is due to the colder air mass in the latter month. Furthermore, some anomalies are observed, such as a relative minimum in June and an absolute maximum in October. The comparison of this behavior with severe weather observations shows two coincidences: the relative maximum in January related to the episode shown in Fig. 6, and a minimum in June coinciding with the lowest of warnings. Regarding hourly distribution (Fig. 10 below), there is a clear relationship between the warnings recorded and the diurnal cycle. A maximum of both types of alert (levels 1 and 2) happens between 12 and 20 UTC. In addition, an absolute maximum occurs between 15 and 17 UTC. However, the alerts recorded during the night (21 to 05 UTC) show no relation to the distribution of the observations. In any case, the phenomena presented during the night are usually not well reported, because the visual capacity is weaker than during the day (Blair et al., 2017; Ashley et al., 2008; Ortega et al., 2009).

\subsection{Climatic analysis of the $2006-2018$ period}

The LJ algorithm was run off-line for the 2006-2018 period. The goals were, on the one hand, to get to know 


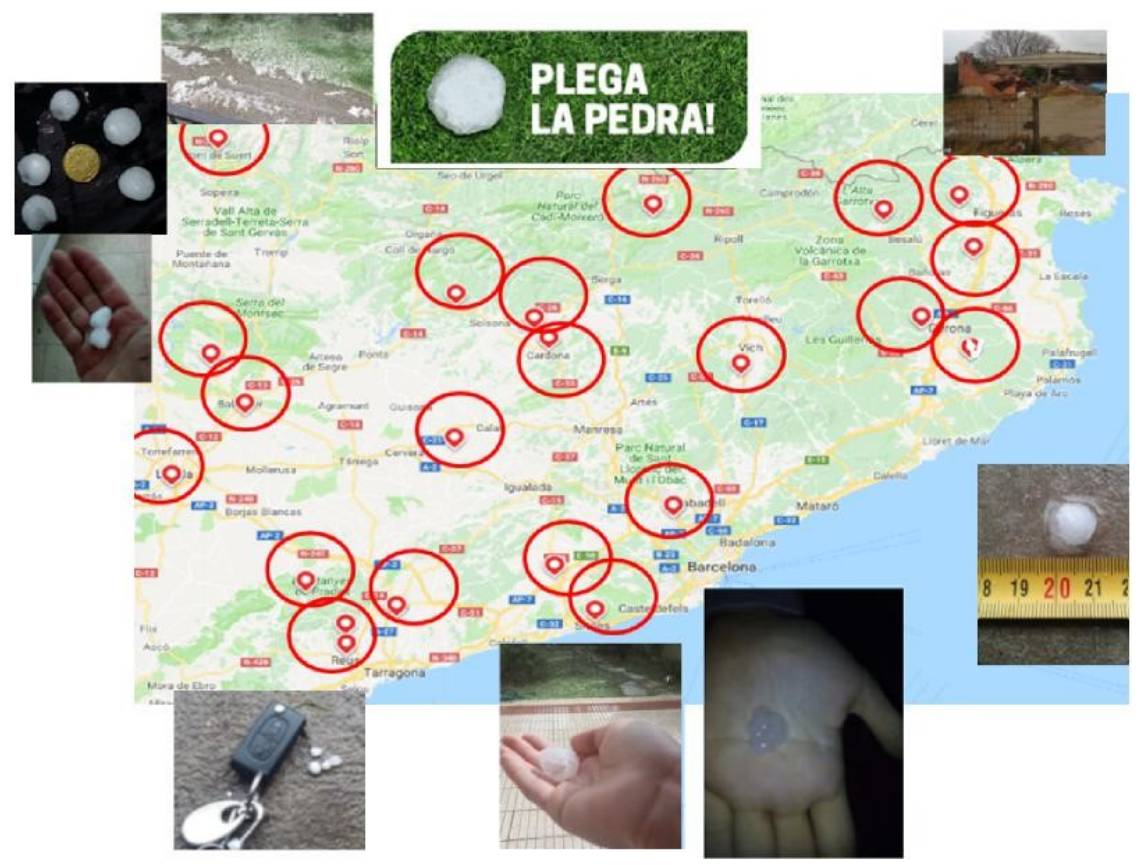

Figure 8: Severe weather observations recorded during the 2018 \#PlegalaPedra campaign, using a viewer of the SMC.

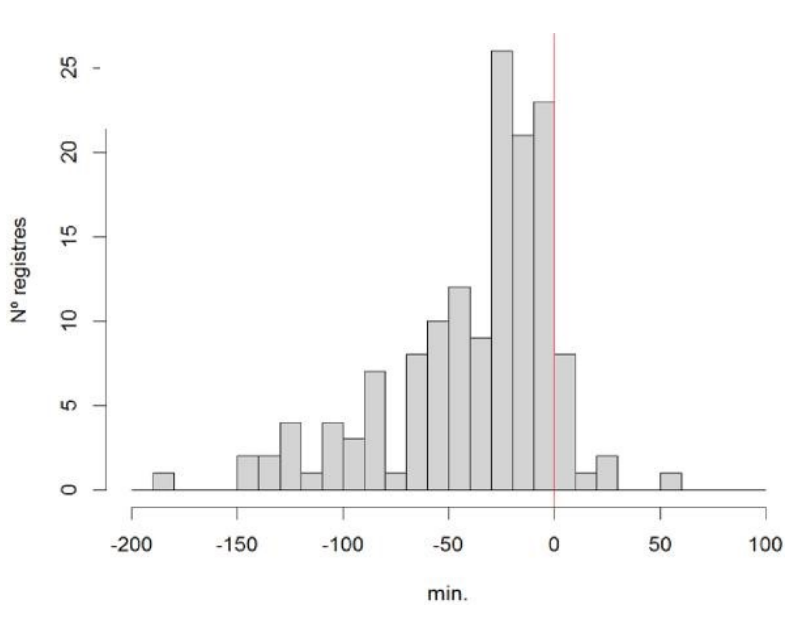

Figure 9: Histogram showing the lead time between the time when the alerts were activated and the observations were recorded.

the behavior of the tool. On the other hand, to make a comparison with the results of the 2018 campaign. Fig. 11 allows a comparison of the results obtained during the 2018 campaign and the 2006-2018 period to be obtained. Regarding spatial distribution, there is a maximum in the Pre-Coastal zone, proving the link between severe weather warnings and topography. The rest of Catalonia's areas can be affected by LJ warnings, but they are less likely in the NE and $\mathrm{S}$ of the coast. The monthly distribution is shown in the right panel considering different percentiles $(5,25,50,75$ and 90). The comparison with Fig. 10 (top) highlights that there is a clear seasonality with more limited activity from November to March.

Fig. 12 shows the monthly distribution divided between non-severe (top) and severe (bottom) events. There are significant differences between them. Firstly, there is a big
Table 1: Distribution of alerts per season ("N,D J,FM" = November to March "A,M,O" = April, May and October; "J,J,A,S" = from June to September), for each level (1 and 2), and for each zone (1,2 and 3).

\begin{tabular}{c|c|c|c|c|c|c}
\hline Season & \multicolumn{2}{|c|}{ N,D,J,F,M } & \multicolumn{2}{c|}{ A,M,O } & \multicolumn{2}{c}{ J,J,A,S } \\
\hline Level & 1 & 2 & 1 & 2 & 1 & 2 \\
\hline Zone 1 & 2 & 0 & 114 & 17 & 696 & 252 \\
Zone 2 & 30 & 4 & 532 & 114 & 2406 & 887 \\
Zone 3 & 77 & 13 & 316 & 70 & 1035 & 448 \\
\hline
\end{tabular}

contribution to LJ1. The ratio was $0.33(\mathrm{LJ} 2)$ to 1 (LJ1). Secondly, the majority of $\mathrm{LJ} 2$ alerts occur between June and September. Its influence is null for the other months. To the contrary, the LJ1 alerts are more significant in April, May, and October. Summing up, three annuals periods are evident and can be differentiated. Firstly, from November to March without warning (less than $2 \%$ ) and a clear dominance of level 1 alerts. The second one, which includes April, March, and October, with more warnings $(16.5 \%$ which represents 30 alerts per month and year), and a ratio of 0.22 level 2 alerts regarding level 1 warnings. The last period goes from June to September, with $81.5 \%$ of the warnings. In this case, the ratio is 0.4 level 2 alerts for each level 1 alert.

The same process was repeated to see the influence of the topography and the Mediterranean Sea on the LJ warning occurrence. The behavior shows different periods of activity, from June to September (zone 1), from May to October (zone 2) and from July to October (zone 3 ). In consequence, the higher the maritime influence, the later in the year the alert is produced. Looking at this topic in greater depth, Table 1 shows a significant contribution of zone 3 (maritime zone) during the cold season (from November to March). The behaviors during the remaining months can be summarized as follows. LJ1 and LJ2 warnings show comparable values 
No. Warnings/month
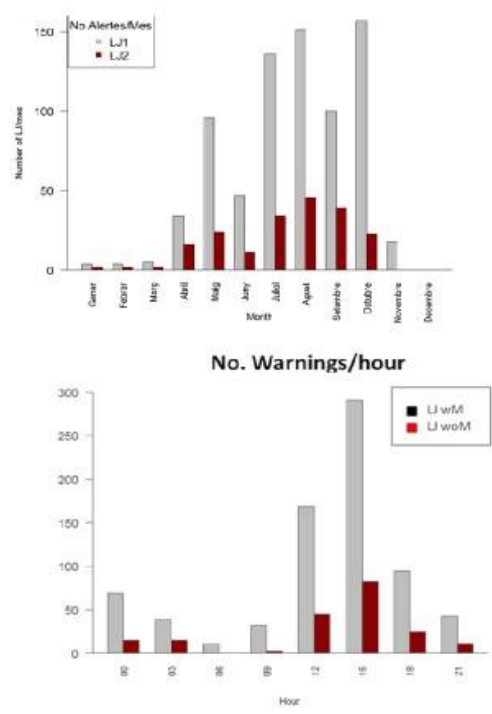

No. Observations/month

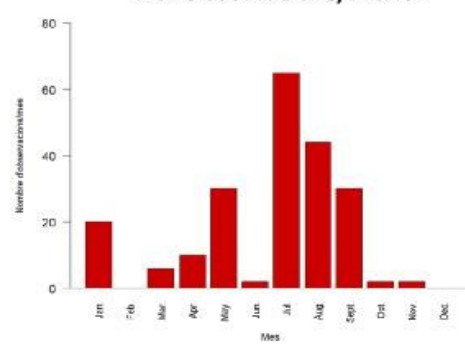

No. Observations/hour

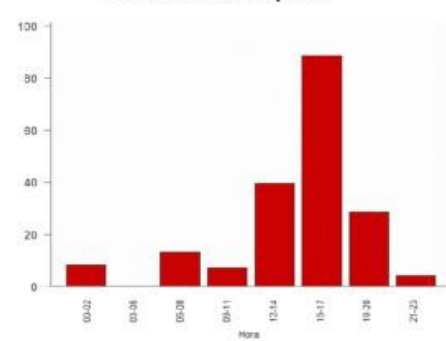

Figure 10: Top: Monthly distribution of LJ1 (gray) and LJ2 (red) for 2018 (left) and 2006-2013 (right). Bottom: The same as above but showing the hourly distribution.
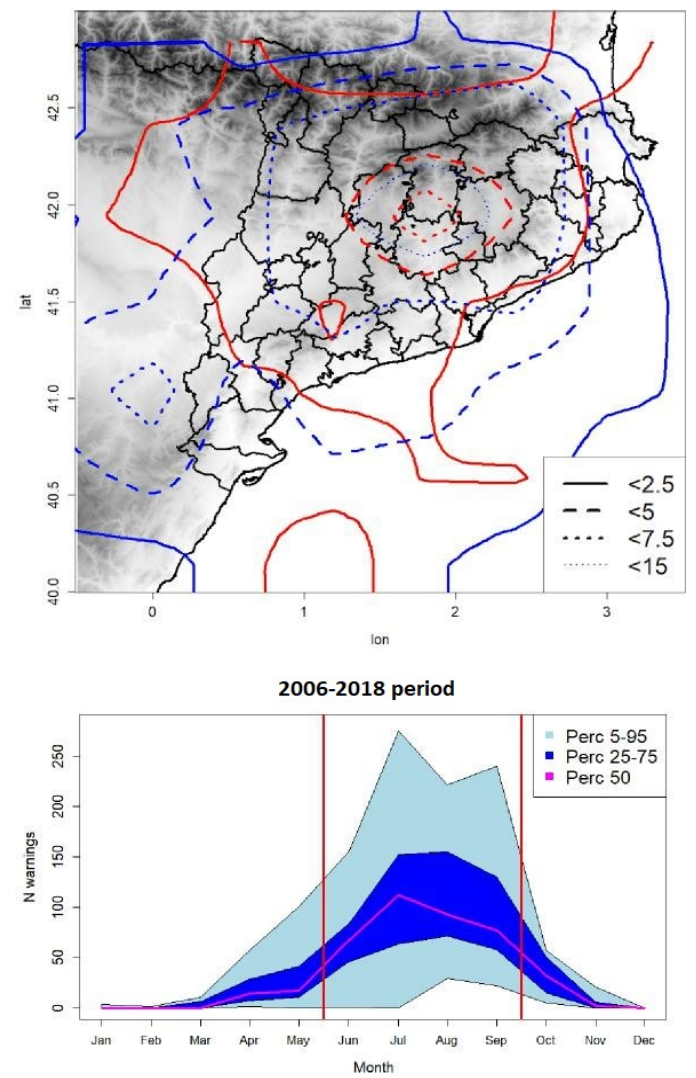

Figure 11: Top: Density plots of alerts recorded during the 2006-2018 period (blue: LJ1, red: LJ2). Bottom: Monthly distribution for all alerts represented through 5, 25, 50,75 and 95 percentile.

in both zones 2 and 3 during the transition season. However, the season with the greatest activity shows coincident ratios for zones 1 and 2, while zone 3 shows different values.

The hourly distributions of the alerts for the different areas (Fig. 13) show different behaviors. In zone 1, the
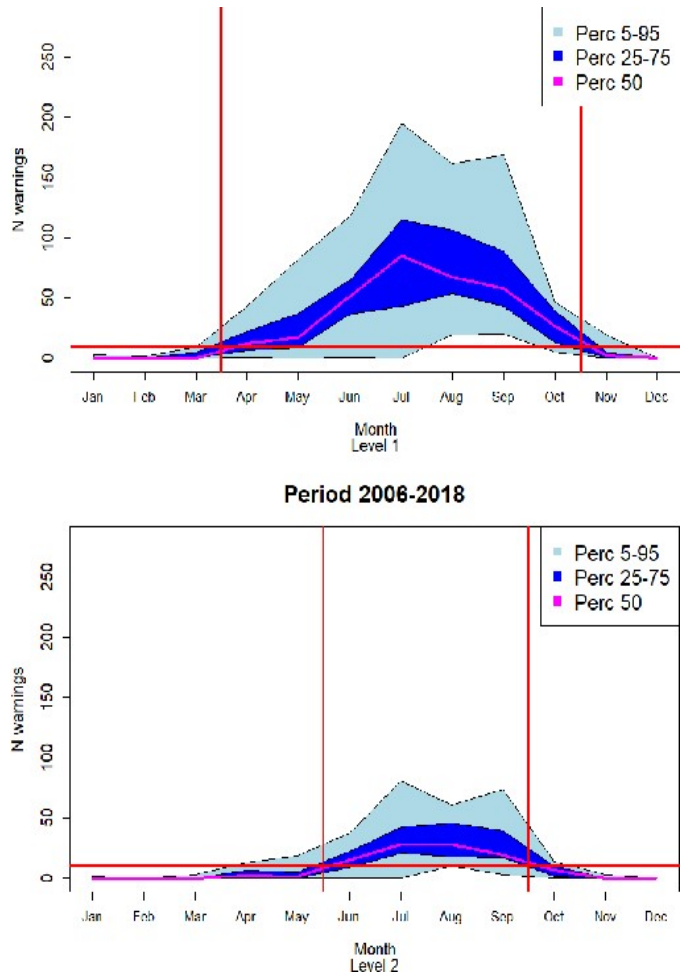

Figure 12: Similar to the right panel of the previous figure for LJ1 alerts (top) and LJ2 alerts (bottom).

LJ1 warnings usually occur between 13 and 18 UTC. The maximum activity is more extensive in zone 2 than in zone 1 , and it goes from 11 to 21 UTC. In both regions, there is a link to the convection of the diurnal cycle. However, the maritime area (zone 3) shows constant activity during the day, without any small peaks. To sum up, the marine influence minimizes the diurnal cycle and causes an active contribution during nocturnal episodes. 

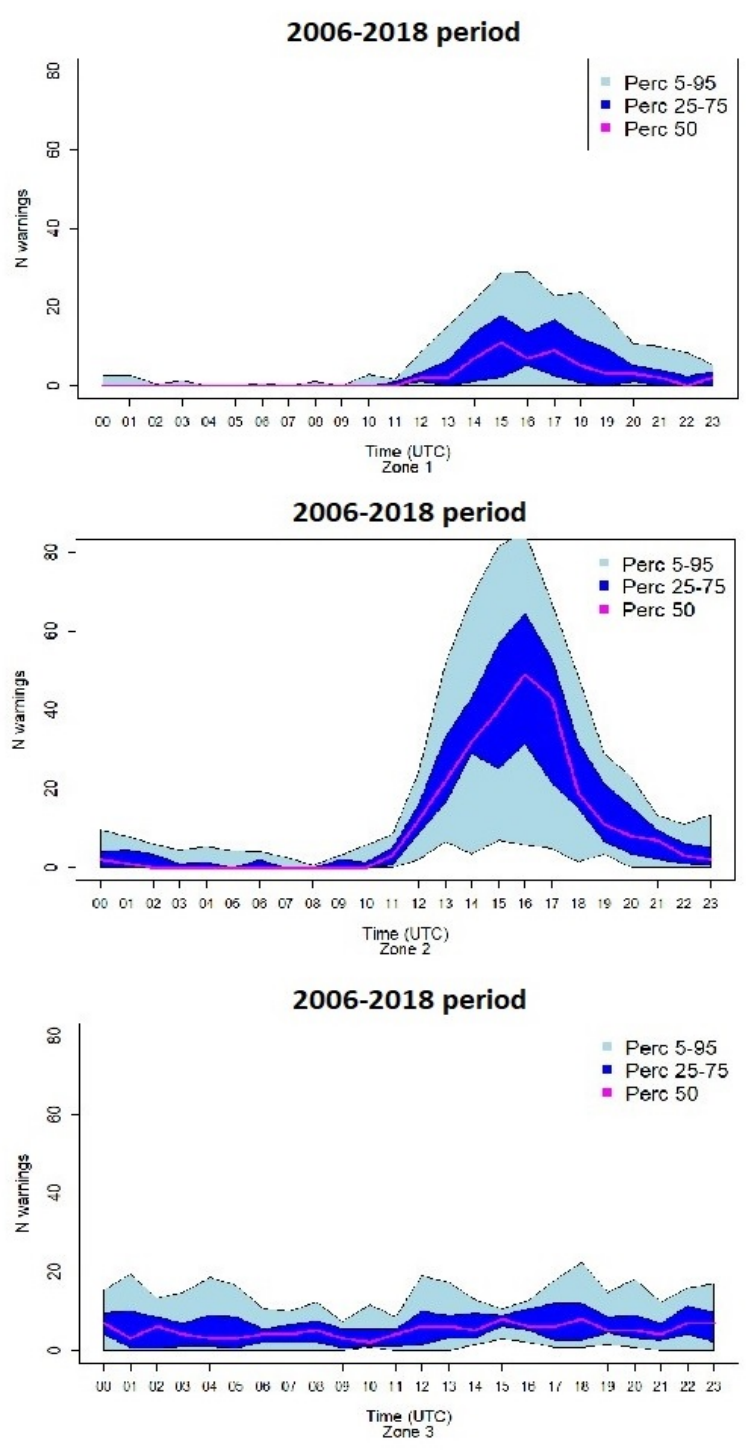

Figure 13: Hourly distribution of all alerts for each zone.

Finally, Fig. 14 shows a scheme of the contribution of the topography and the sea regarding the convection activity in this area. The left panel shows the annual distribution of average temperature close to the coastline, over the land (LST, in red, data obtained from the Automatic Weather Stations network of the SMC) and over the sea (SST, in blue, data obtained by satellite AVHRR, (Casey et al., 2010). The points indicate the difference of temperatures $-0.5^{\circ} \mathrm{C}$ (yellow), between -0.5 and $-2{ }^{\circ} \mathrm{C}$ (light green), and below $-2^{\circ} \mathrm{C}$ (green). The left panel of Fig. 14 shows three periods: "cold" (dark green) from October to February; "transition" (light green) between March and April and, "warm" (yellow) from May to August. This pattern is coincident with that shown in Fig. 11. Moreover, it has combined the difference of temperatures with the topography associated with the LJ occurrence (right panel Fig. 14), in other words, the height where the warnings have occurred: quantile area 5-95
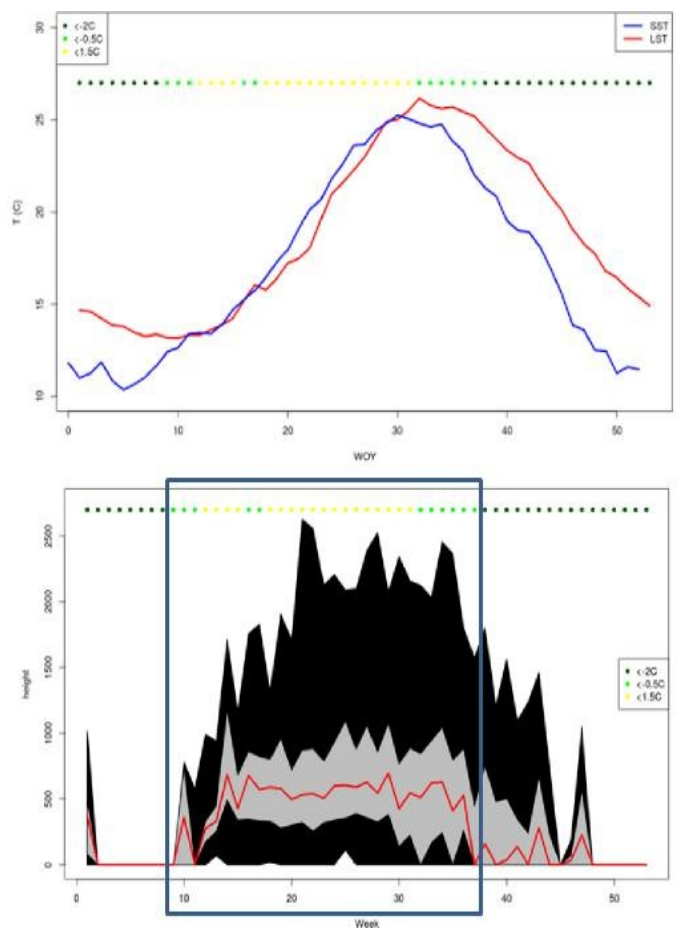

Figure 14: Top: Daily distribution of sea temperatures and the coast. Bottom: Height where the alert was produced during the year: red line indicates average value, while 25-75 percentiles are shown in gray, $10-90$ percentiles, in black.

(black) and 25-75 (grey) and quantile 50 (red line). During the transition and warm periods (blue square), the alerts are recorded in mountain areas (mountains with an average height of around $500 \mathrm{~m}$ ), while in the cold period the height drops to the sea level.

\section{Conclusions}

This paper summarizes the results of the first operational campaign of the LJ algorithm at the Servei Meteorològic de Catalunya. Using only lightning data, forecasters have the information more than 10 minutes before the combination of radar and lightning has been considered. However, the capacity for identifying the thunderstorm is lower in the current version of the algorithm. Another interesting point is that the SMC operational algorithm does not consider any total lightning threshold. This is because the authors' experience has led us to see that the continuity in time and space over 14 minutes are sufficient to identify a convective cell as potentially severe.

Most of the severe thunderstorms triggered LJ warnings with a lead time of over 30 minutes during 2018. However, severe weather registers did not occur in all cases or, at least, they were not observed or reported. In addition, from the comparison with automatic weather stations or remote sensing data, it has been observed how, in some cases, the reports indicated the wrong time. Because of this, the SMC started a citizen campaign (\#meteocatpedra) with different objectives: to receive more and better reports of the events; to improve 
knowledge about the phenomena on the ground; and, finally, to create awareness among the population about hail facts. Using the data provided with a correct filter, it is possible to improve the verification technique of the LJ algorithm.

Monthly and time distributions of the warnings show high coincidences with the observations reported. This demonstrates the great relationship between the LJ and the severe weather occurrence on the surface. Moreover, despite the improvement of the results from the citizen campaign, it has been observed that areas with low-density population and events that occurred at night still have validation difficulties. The number of warnings of level 2 (without a multiplicity of the strokes and associated with severe weather) is less than a third that in the case of level 1.

The last part of the analysis focused on the 2006-2018 period. Level 1 warnings occur mainly from April to October, while level 2 is concentrated on the period between June and September. There is also a close relationship between the alerts and the diurnal cycle of convection in those areas influenced by the topography. Finally, the sea surface temperature seems to play an important role in those cases in which the topography has less impact.

\section{References}

Aran, M., Amaro, J., Arús, J., Bech, J., Figuerola, F., Gayà, M., and Vilaclara, E., 2009: Synoptic and mesoscale diagnosis of a tornado event in Castellcir, Catalonia, on 18th October 2006, Atmos. Res., 93, 147-160.

Ashley, W. S., Krmenec, A. J., and Schwantes, R., 2008: Vulnerability due to nocturnal tornadoes, Weather Forecast., 23, 795-807.

Blair, S. F., Laflin, J. M., Cavanaugh, D. E., Sanders, K. J., Currens, S. R., Pullin, J. I., Cooper, D. T., Deroche, D. R., Leighton, J. W., Fritchie, R. V., et al., 2017: High-resolution hail observations: Implications for NWS warning operations, Weather Forecast., 32, 1101-1119.

Bridenstine, P. V., Darden, C. B., Burks, J., and Goodman, S. J., 2005: The application of total lightning data in the warning decision making process, in: Preprints, 2nd Conf. on Meteorological Applications of Lightning Data, San Diego, CA, Amer. Meteor. Soc. CD-ROM P, vol. 1.

Casey, K. S., Brandon, T. B., Cornillon, P., and Evans, R.: The past, present, and future of the AVHRR Pathfinder SST program, in: Oceanography from space, pp. 273-287, Springer, 2010.

Crum, T. D., Saffle, R. E., and Wilson, J. W., 1998: An update on the NEXRAD program and future WSR-88D support to operations, Weather Forecast., 13, 253-262.

Darden, C. B., Nadler, D. J., Carcione, B. C., Blakeslee, R. J., Stano, G. T., and Buechler, D. E., 2010: Utilizing total lightning information to diagnose convective trends, Bull. Amer. Meteorol. Soc., 91, 167-176.

del Moral, A., Rigo, T., and Llasat, M. C., 2018: A radar-based centroid tracking algorithm for severe weather surveillance: Identifying split/merge processes in convective systems, Atmos. Res., 213, 110-120.
Dixon, M. and Wiener, G., 1993: TITAN: Thunderstorm identification, tracking, analysis, and nowcasting $-A$ radarbased methodology, J. Atmos. Ocean. Technol., 10, 785-797.

Ducrocq, V., Braud, I., Davolio, S., Ferretti, R., Flamant, C., Jansa, A., Kalthoff, N., Richard, E., Taupier-Letage, I., Ayral, P.-A., et al., 2014: HyMeX-SOP1: The field campaign dedicated to heavy precipitation and flash flooding in the northwestern Mediterranean, Bull. Amer. Meteorol. Soc., 95, 1083-1100.

Farnell, C., Rigo, T., and Pineda, N., 2017: Lightning jump as a nowcast predictor: Application to severe weather events in Catalonia, Atmos. Res., 183, 130-141.

Farnell, C., Rigo, T., and Pineda, N., 2018: Exploring radar and lightning variables associated with the Lightning Jump. Can we predict the size of the hail?, Atmos. Res., 202, 175-186.

Gabella, M., Boscacci, M., Sartori, M., and Germann, U., 2016: Calibration accuracy of the dual-polarization receivers of the $C$ band Swiss weather radar network, Atmosphere, 7, 76.

Gatlin, P. N. and Goodman, S. J., 2010: A total lightning trending algorithm to identify severe thunderstorms, J. Atmos. Ocean. Technol., 27, 3-22.

Hijmans, R.: Package 'raster'. Geographic Data Analysis and Modeling. R package version 2.8-19, 2017.

Jansa, A., Genoves, A., and Garcia-Moya, J. A., 2000: Western Mediterranean cyclones and heavy rain. Part 1: Numerical experiment concerning the Piedmont flood case, Meteorol. Appl., 7, 323-333.

Johnson, J., MacKeen, P. L., Witt, A., Mitchell, E. D. W., Stumpf, G. J., Eilts, M. D., and Thomas, K. W., 1998: The storm cell identification and tracking algorithm: An enhanced WSR-88D algorithm, Weather Forecast., 13, 263-276.

Llasat, M., Cortès Simó, M., and Llasat, M. C., 2018: FLOODUP. Una herramienta para aumentar la información y mejorar el conocimiento colectivo sobre eventos meteorológicos extremos.

Llasat Botija, M. C., Llasat-Botija, M., Prat Sabartés, M., Porcu, F., Price, C., Mugnai, A., Lagouvardos, K., Kotroni, V., Katsanos, D., Michaelides, S., et al., 2010: High-impact floods and flash floods in Mediterranean countries: the FLASH preliminary database, Adv. Geosci., 23, 47-55.

López, J. M., 2007: A Mediterranean derecho: Catalonia (Spain), 17th August 2003, Atmos. Res., 83, 272-283.

Ortega, K. L., Smith, T. M., Manross, K. L., Scharfenberg, K. A., Witt, A., Kolodziej, A. G., and Gourley, J. J., 2009: The severe hazards analysis and verification experiment, Bull. Amer. Meteorol. Soc., 90, 1519-1530.

Ortega, K. L., Krause, J. M., and Ryzhkov, A. V., 2016: Polarimetric radar characteristics of melting hail. Part III: Validation of the algorithm for hail size discrimination, J.Appl. Meteorol. Climatol., 55, 829-848.

Pascual, R., 2000: Granizo en el llano de Lleida, INM. Tempoweb training module.

Pascual, R., Callado, A., and Berenguer, M., 2004: Convective storm initiation in central Catalonia, Proc. of ERAD04, pp. 464468.

Pineda, N., Rigo, T., Montanyà, J., and van der Velde, O. A., 2016: Charge structure analysis of a severe hailstorm with predominantly positive cloud-to-ground lightning, Atmos. Res., 178, 31-44.

Price, C. G., 2013: Lightning applications in weather and climate research, Surv. Geophys., 34, 755-767. 
Ramis, C., Arús, J., López, J. M., and Mestres, A. M., 1997: Two cases of severe weather in Catalonia (Spain): an observational study, Meteorol. Appl., 4, 207-217.

$\mathrm{R}$ Core Team: $R$ : A language and environment for statistical computing, 2013.

Rigo, T. and Llasat, M. C., 2016: Forecasting hailfall using parameters for convective cells identified by radar, Atmos. Res., 169, 366-376.

Schultz, C. J., Petersen, W. A., and Carey, L. D., 2009: Preliminary development and evaluation of lightning jump algorithms for the real-time detection of severe weather, J. Appl. Meteorol. Climatol., 48, 2543-2563.

Schultz, C. J., Petersen, W. A., and Carey, L. D., 2011: Lightning and severe weather: A comparison between total and cloud-toground lightning trends, Weather Forecast., 26, 744-755.

Stano, G., Schlutz, C., Carey, L., Macgorman, D., and Calhoun, K., 2014: Total Lightning Observations and Tools for the 20 May 2013 Moore, Oklahoma, Tornadic Supercell., J. Operational Meteorol., 2.

Tudurí, E. and Ramis, C., 1997: The environments of significant convective events in the western Mediterranean, Weather Forecast., 12, 294-306.

Williams, E., Boldi, B., Matlin, A., Weber, M., Hodanish, S., Sharp, D., Goodman, S., Raghavan, R., and Buechler, D., 1999: The behavior of total lightning activity in severe Florida thunderstorms, Atmos. Res., 51, 245-265.

Yao, W., Zhang, Y., Meng, Q., Wang, F., and Lu, W., 2013: A comparison of the characteristics of total and cloud-to-ground lightning activities in hailstorms, Acta Meteorologica Sinica, 27, 282-293. 